\title{
Surgical Treatment of Melanoma: A Survey of Italian Hospitals
}

\author{
Alessandro Testori ${ }^{a}$ Vanna Chiarion-Sileni ${ }^{b}$ Ignazio Stanganellic \\ Carlo Riccardo Rossi $^{d}$ Franco Di Filippo ${ }^{\text {e }}$ Ruggero Ridolfi ${ }^{f}$ Giorgio Parmianig \\ Sara Gandinia Javier Soteldo ${ }^{a}$

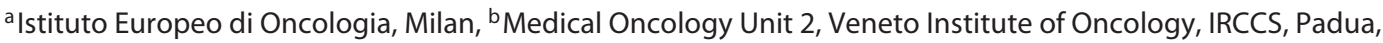 \\ 'Scientific Institute of Romagna for the Study and Treatment of Tumors, Meldola, ' General Surgery Clinic, \\ Department of Oncological and Surgical Sciences, University of Padua, Padua, ${ }^{\mathrm{e}}$ General Surgery, National Cancer

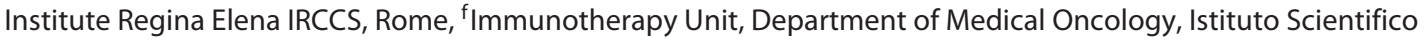 \\ Romagnolo per lo Studio e la Cura dei Tumori, Meldola, and 9 Unit of Immuno-Biotherapy of Melanoma and Solid \\ Tumors, San Raffaele Foundation Scientific Institute, Milan, Italy
}

\section{Key Words}

Melanoma · Surgery · Incision margins · Lymph node biopsy

\section{Abstract}

Surgery is the first option for treating melanoma regardless of stage at presentation. We surveyed a representative sample of hospitals to evaluate management and quality of surgical indications for melanoma in Italy. At analysis, hospitals were grouped into high- or low-volume centers, with the population median of 25 diagnoses serving as the cut-off. Surgery for primary melanoma was similar between hospital groups. More high-volume centers were organized to perform sentinel node biopsy (91 vs. 56\%). There were no major differences between high- and low-volume centers concerning the surgical approach to stage III and IV disease.

Copyright $\odot 2013$ S. Karger AG, Basel

\section{KARGER}

E-Mail karger@karger.com

www.karger.com/drm

\section{Introduction}

Surgery is the only effective therapy for melanoma, but its usefulness is mainly limited to early stages. Treatment of primary melanoma consists of excision of the tumor or surgical scar of a previous biopsy en bloc with apparently healthy cutaneous and subcutaneous margins down to the muscle sheath, which is normally conserved as there is no evidence of a benefit from removing it [1-6]. Current guidelines on resection margins are based on the results of randomized trials: WHO Melanoma Trial No. 10 [7], Intergroup Melanoma Trial [8], Swedish MSG Trial [9], European Trial [10] and UK Trial [11]. All of these had two arms, one with patients treated with narrow resection margins and one with wider margins. All patients had histologically confirmed melanoma and did not have invasive disease at staging. Meta-analyses of these trials do not reveal statistically significant differences in terms of mortality or local recurrence according to the width of resection margins [12-14].

Therefore, integrating the data emerging from these trials, the following margins are recommended: (1) melano- 
ma in situ: $0.5 \mathrm{~cm}$; (2) melanoma $<1 \mathrm{~mm}: 1 \mathrm{~cm}$; (3) melanoma 1-2 mm: $1 \mathrm{~cm}$; (4) melanoma 2-4 mm: $2 \mathrm{~cm}$; (5) melanoma $>4 \mathrm{~mm}: 2 \mathrm{~cm}$. The only exception is for particular anatomical locations such as the face, where much narrower margins can be maintained to avoid excessive damage. Moreover, in the case of lentigo maligna, definitive histological confirmation of clean margins is of fundamental importance, since the resection margins are very narrow.

\section{Sentinel Lymph Node Biopsy}

In 1992 Donald Morton [15] published the first report on a method for intra-operative lymphatic mapping with Patent Blue staining, which has a reported sensitivity of $69-92 \%$. Sensitivity can be improved to nearly $100 \%$ by identifying the drainage basin pre-operatively with lymphatic scintigraphy and using an intra-operative radionuclide probe to identify the sentinel lymph node (SLN). Numerous studies have investigated the best procedure for and biological significance of SLN biopsy in melanoma.

In the MSLT-I trial patients had primary tumors excised and then underwent either clinical monitoring of lymph nodes or SLN biopsy. Although the results confirmed the high sensitivity of SLN biopsy and showed that it is the most significant prognostic factor, there was no survival benefit [16].

The SOLISM study examined 1,300 patients with Breslow thicknesses $>1 \mathrm{~mm}$ or Clark levels $>$ IV and contributed to standardizing procedures for lymphatic scintigraphy, the use of vital dyes and surgical techniques, among other aspects [17].

Currently SLN biopsy is performed in patients with Breslow thicknesses $\geq 1 \mathrm{~mm}$ with associated histopathology, or with Breslow thicknesses $<1 \mathrm{~mm}$, but with ulceration or high mitotic indexes; Clark levels (specifically in case of IV or $\mathrm{V}$ ) are no more considered of prognostic significance in the last AJCC classification. Generally, centers not participating in the MSLT-II trial (NCT00297895) follow the consolidated guidelines: patients with negative SLN are monitored with clinical follow-up, while SLN-positive patients, including those with micrometastases, are subjected to complete lymph node dissection.

Lymph Node Dissection (Axillary, Inguinal-Iliac-

Obturator, Popliteal, Epitrochlear)

According to the surgical guidelines lymph node dissection should be performed with a positive SLN result or documented lymphatic metastasis; the extension of lymph node metastases has not been universally accepted in all the basins frequently involved in dissection areas $[18,19]$.

\section{Metastases in Transit}

Melanomas that spread in the lymphatic system and develop lesions in the soft tissue before reaching a locoregional lymph node are known as in transit metastases. These may take the form of cutaneous or subcutaneous nodules. Surgery is indicated if there is/are only one/few metastatic lesion/s. If metastases are numerous or recur rapidly after removal and are located in the limbs, hyperthermic isolated limb perfusion (ILP) is administered to cause tumor regression. Electrochemotherapy (ECT) is a new treatment modality for cutaneous and subcutaneous metastases of numerous tumors, including melanoma. ECT increases antitumoral efficacy by combining a chemotherapeutic with electroporation, which increases cell membrane permeability and hence drug uptake [20-23].

\section{Distant Metastases}

Stage IV metastatic melanoma, as for other tumors, is the phase of the disease with distant metastases. The metastases occur most frequently to the liver, lung, brain, small bowel and bones. Unfortunately, survival in this stage of the disease is very low, with a mean overall survival of a few months.

\section{Methods}

Briefly, a nationwide survey of clinicians responsible for the diagnosis, therapy or follow-up phases of melanoma care in Italian hospitals was conducted. Italian hospitals with $\geq 200$ beds $(n=285)$ were subdivided into 145 hospitals with $200-399$ beds and 140 hospitals with $\geq 400$ beds and a proportionally stratified random sample $(n=120$ centers), stratified by number of beds and geographic distribution, was selected. Two or three clinicians were interviewed at each center, resulting in approximately 250 interviews and a predicted margin of error - $95 \%$ confidence level - of $7.7 \%$.

Based on the findings, centers were grouped by number of new melanoma diagnoses per year into low- and high-volume centers, around the median value of 25 . Variables were analyzed in the total sample/total Italian hospitals, and comparisons were made between high- and low-volume centers using Pearson's $\chi^{2}$ test and the zeta test at $95 \%$ confidence level. Detailed methods are presented elsewhere in this supplement [24].

\section{Results}

\section{Primary Melanoma}

Our data show that the indications from clinical trials are being followed in both high- and low-volume centers; margins are based on Breslow thickness. There were no major differences among Italian hospitals regarding resection margins. 


\section{Sentinel Lymph Node Biopsy}

There were several important differences between the high- and low-volume centers regarding SLN biopsy: while $91 \%$ of high-volume centers use SLN biopsy, it is used in only $56 \%$ of low-volume centers $(\mathrm{p}<0.001$ ). Among centers that do not perform SLN biopsies, all of the high-volume centers have agreements with referral centers for this service, while only $81 \%$ of low-volume centers do, meaning that in nearly one fifth of the lowvolume centers, patients must find adequate care on their own.

Regarding biopsy methods, a majority of high-volume centers use the Gamma Probe with Patent Blue dye (69\%), while in low-volume centers the Gamma Probe is used somewhat more often without Patent Blue (79\%). Concerning the Breslow thickness cut-off for indicating SLN biopsy, the results are the same for melanomas between 1 and $4 \mathrm{~mm}(85 \%)$ and statistically different in those $>4 \mathrm{~mm}$, where they are performed in more of the lowvolume centers ( 92 vs. $79 \%, p=0.006$ ). For Breslow values $<1 \mathrm{~mm}$ the results were similar in both groups, with the exception of Clark levels IV/V, which triggered biopsy in $71 \%$ of high-volume centers and $49 \%$ of low-volume centers $(p=0.01)$. Results were similar between groups for indications in case of regression $(79 \%)$, or patient selection (15\%), remaining low for both ulcerated (46\%) and nodular (54\%) melanomas.

When a primary melanoma is located between the zygomatic arch and the mastoid, $91 \%$ of high-volume centers perform SLN biopsy, compared to $56 \%$ of low-volume centers ( $p<0.001)$. The type of intervention is similar (superficial parotidectomy) and is mainly performed when there is documented metastasis.

\section{Stage III Disease}

Results were similar in both groups. Axillary dissection on three levels is performed for macrometastases in $80 \%$ of centers and for micrometastases in $65 \%$. When IHC/PCR is positive, all three levels are dissected in $40 \%$ of cases. Regarding the neck area, whether macro-/micrometastases or IHC/PCR-positive cases are present, radical dissection or modified radical dissection is performed, with no difference in the procedures. Regarding the inguinal-iliac-obturator nodes, the only significant difference between groups was when Cloquet's node is positive for micrometastases, in which case inguinal-iliac-obturator dissection was performed more frequently in low-volume centers ( 59 vs. $37 \%, \mathrm{p}=0.01$ ). All other conditions were similar between groups.
ECT is used in $24 \%$ of high-volume centers and $15 \%$ of low-volume centers, with few differences according to indication: for metastases in transit and rapidly relapsing or inoperable cases (79-65\%), however, it was used more frequently for a first metastasis in transit presenting in low-volume centers ( 35 vs. $13 \%, p=0.03$ ). It appears to be used when ILP is no longer indicated, in which case the hospitals are equally divided between traditional surgery and medical therapy. Instead, among hospitals that perform ILP we found that low-volume centers use it more frequently for a first metastasis in transit ( 83 vs. $58 \%$, p < $0.001)$.

\section{Stage IV Disease}

In these cases both high- and low-volume centers are in agreement in treating single visceral and small superficial metastases with surgery. High-volume centers were more likely to use palliative surgery $(\mathrm{p}=0.001)$.

\section{Discussion}

Our analysis of surgical approaches to melanoma treatment in Italian hospitals did not reveal major differences between high- and low-volume centers. The most important differences were in the organization of specific treatments that require a dedicated and multidisciplinary approach, like SLN biopsy and ILP. It is understandable that institutions treating few patients would not be organized to perform such procedures.

There were several important differences between centers regarding SLN biopsy. The tendency to use the Gamma Probe without Patent Blue dye in low-volume centers would not appear to be an important difference because the association of Patent Blue serves mainly to facilitate the surgical procedure. Regarding Breslow thicknesses $>4 \mathrm{~mm}$, interpretation of our data should consider the clinical studies on such patients. In fact, there is ongoing debate over the indication for SLN biopsy in such patients, some holding that the overall poor prognosis at this stage is no longer guided by lymph node involvement. This may be an excessively rigid interpretation lacking biological justification, since a negative SLN result would indicate better prognosis for a given Breslow thickness.

Regarding ILP, it is noteworthy that while more highvolume centers perform such procedures ( 24 vs. 11\%), overall the number is very small. Where ILP is not performed, there is agreement in both types of centers that it be indicated for inoperable or rapidly relapsing metastases in transit. The significant difference between high-
Testori et al. 
and low-volume centers in requesting ILP for a first metastasis in transit (13 vs. $35 \%$ ) is likely to be due to the level of experience with this pathology. Generally the indication for ILP is multiple or rapidly recurring metastases, which obviously is not the case for a first metastatic manifestation. When, instead, patients are not referred for ILP, both types of centers divide patients equally between medical and surgical treatments. ECT is being used with gradually increasing frequency and the methodolo- gy is established in the European Standard Operating Procedures of Electrochemotherapy (ESOPE) guidelines [23].

\section{Disclosure Statement}

The authors have no disclosure in relation to this subject.

\section{References}

1 Karakousis CP, Balch CM, Urist MM, Ross MM, Smith TJ, Bartolucci AA: Local recurrence in malignant melanoma: long-term results of the multiinstitutional randomized surgical trial. Ann Surg Oncol 1996;3:446452.

2 Veronesi U, Cascinelli N: Narrow excision (1-cm margin). A safe procedure for thin cutaneous melanoma. Arch Surg 1991;126:438441.

>3 Heaton KM, Sussman JJ, Gershenwald JE, Lee JE, Reintgen DS, Mansfield PF, Ross MI: Surgical margins and prognostic factors in patients with thick $(>4 \mathrm{~mm})$ primary melanoma. Ann Surg Oncol 1998;5:322-328.

4 Stage I melanoma of the skin: the problem of resection margins. W.H.O. Collaborating Centres for Evaluation of Methods of Diagnosis and Treatment of Melanoma. Eur J Cancer 1980;16:1079-1085.

5 Whooley BP, Wallack MK: Surgical management of melanoma. Surg Oncol 1995;4:187195.

6 Ross MI: Surgery and other local-regional modalities for all stages of melanoma. Curr Opin Oncol 1994;6:197-203.

-7 Veronesi U, Cascinelli N, Adamus J, Balch C, Bandiera D, Barchuk A, Bufalino R, Craig P, De Marsillac J, Durand JC, et al: Thin stage I primary cutaneous malignant melanoma. Comparison of excision with margins of 1 or $3 \mathrm{~cm}$. N Engl J Med 1988;318:1159-1162.

8 Balch CM, Urist MM, Karakousis CP, Smith TJ, Temple WJ, Drzewiecki K, Jewell WR, Bartolucci AA, Mihm MC Jr, Barnhill R, et al: Efficacy of 2-cm surgical margins for intermediate-thickness melanomas ( 1 to $4 \mathrm{~mm}$ ). Results of a multi-institutional randomized surgical trial. Ann Surg 1993;218:262-267.

-9 Cohn-Cedermark G, Rutqvist LE, Andersson $\mathrm{R}$, Breivald $\mathrm{M}$, Ingvar $\mathrm{C}$, Johansson $\mathrm{H}$, Jönsson PE, Krysander L, Lindholm C, Ringborg $\mathrm{U}$ : Long term results of a randomized study by the Swedish Melanoma Study Group on $2-\mathrm{cm}$ versus $5-\mathrm{cm}$ resection margins for patients with cutaneous melanoma with a tumor thickness of $0.8-2.0 \mathrm{~mm}$. Cancer $2000 ; 89$ : 1495-1501.
10 Gillgren P, Drzewiecki KT, Niin M, Gullestad HP, Hellborg H, Månsson-Brahme E, Ingvar C, Ringborg U: $2-\mathrm{cm}$ versus 4 - $\mathrm{cm}$ surgical excision margins for primary cutaneous melanoma thicker than $2 \mathrm{~mm}$ : a randomised, multicentre trial. Lancet 2011;378:1635-1642.

11 Thomas JM, Newton-Bishop J, A'Hern R, Coombes G, Timmons M, Evans J, Cook M, Theaker J, Fallowfield M, O’Neill T, Ruka W, Bliss JM; United Kingdom Melanoma Study Group; British Association of Plastic Surgeons; Scottish Cancer Therapy Network: Excision margins in high-risk malignant melanoma. N Engl J Med 2004;350:757-766.

-12 Sladden MJ, Balch C, Barzilai DA, Berg D, Freiman A, Handiside T, Hollis S, Lens MB, Thompson JF: Surgical excision margins for primary cutaneous melanoma. Cochrane $\mathrm{Da}$ tabase Syst Rev 2009;4:CD004835.

13 Lens MB, Nathan P, Bataille V: Excision margins for primary cutaneous melanoma: updated pooled analysis of randomized controlled trials. Arch Surg 2007;142:885-891.

14 Haigh PI, DiFronzo LA, McCready DR: Optimal excision margins for primary cutaneous melanoma: a systematic review and metaanalysis. Can J Surg 2003;46:419-426.

15 Morton DL, Wen DR, Wong JH, Economou JS, Cagle LA, Storm FK, Foshag LJ, Cochran AJ: Technical details of intraoperative lymphatic mapping for early stage melanoma. Arch Surg 1992;127:392-399.

16 Morton DL, Cochran AJ, Thompson JF, Elashoff R, Essner R, Glass EC, Mozzillo N, Nieweg OE, Roses DF, Hoekstra HJ, Karakousis CP, Reintgen DS, Coventry BJ, Wang HJ; Multicenter Selective Lymphadenectomy Trial Group: Sentinel node biopsy for earlystage melanoma: accuracy and morbidity in MSLT-I, an international multicenter trial. Ann Surg 2005;242:302-311.
17 Rossi CR, De Salvo GL, Trifirò G, Mocellin S, Landi G, Macripò G, Carcoforo P, Ricotti G, Giudice G, Picciotto F, Donner D, Di Filippo F, Montesco MC, Casara D, Schiavon M, Foletto M, Baldini F, Testori A: The impact of lymphoscintigraphy technique on the outcome of sentinel node biopsy in 1,313 patients with cutaneous melanoma: an Italian Multicentric Study (SOLISM-IMI). J Nucl Med 2006;47:234-241.

18 Karakousis CP: Ilioinguinal lymph node dissection. Am J Surg 1981;141:299-303.

19 Testori A, Rutkowski P, Marsden J, Bastholt L, Chiarion-Sileni V, Hauschild A, Eggermont AM: Surgery and radiotherapy in the treatment of cutaneous melanoma. Ann Oncol 2009;20(suppl 6):vi22-vi29.

20 Testori A, Tosti G, Martinoli C, Spadola G, Cataldo F, Verrecchia F, Baldini F, Mosconi M, Soteldo J, Tedeschi I, Passoni C, Pari C, Di Pietro A, Ferrucci PF: Electrochemotherapy for cutaneous and subcutaneous tumor lesions: a novel therapeutic approach. Dermatol Ther 2010;23:651-661.

21 Testori A, Faries MB, Thompson JF, Pennacchioli E, Deroose JP, van Geel AN, Verhoef C, Verrecchia F, Soteldo J: Local and intralesional therapy of in-transit melanoma metastases. J Surg Oncol 2011;104:391-396.

22 Testori A, Verhoef C, Kroon HM, Pennacchioli E, Faries MB, Eggermont AM, Thompson JF: Treatment of melanoma metastases in a limb by isolated limb perfusion and isolated limb infusion. J Surg Oncol 2011;104:397-404.

23 Mir LM, Gehl J, Sersa G, Collins CG, Garbay JR, Billard V, et al: Standard operating procedures of the electrochemotherapy: instructions for the use of bleomycin or cisplatin administered either systemically or locally and electric pulses delivered by the Cliniporator ${ }^{\mathrm{TM}}$ by means of invasive or non-invasive electrodes. EJC Suppl 2006;4:14-25.

24 Mingozzi E, Fregosi S, Gandini S, Stanganelli I, Chiarion-Sileni V, Testori A: Melanoma Task Force (META) project in Italy: methodology. Dermatology 2013;226(suppl 1): $1-2$. 